\title{
Current Status of Extended Adjuvant Endocrine Therapy in Early Stage Breast Cancer
}

Irene E. G. van Hellemond, MD

Sandra M. E. Geurts, Msc, PhD

Vivianne C. G. Tjan-Heijnen, MD, PhD ${ }^{*}$

\author{
Address \\ "Division Medical Oncology, GROW - School of Oncology and Developmental \\ Biology, Maastricht University Medical Centre, P.0. Box 5800, 6202 AZ, Maas- \\ tricht, The Netherlands \\ Email:vcg.tjan.heijnen@mumc.nl
}

Published online: 27 April 2018

(C) The Author(s) 2018

\section{This article is part of the Topical Collection on Breast Cancer}

Keywords Endocrine therapy - Aromatase inhibitor - Tamoxifen · Adjuvant therapy · Breast cancer - Postmenopausal

\section{Opinion statement}

In the past decade, several endocrine treatment regimens have been developed for the adjuvant treatment of postmenopausal women with hormone receptor-positive early breast cancer, including tamoxifen, aromatase inhibitors (AI), or a combination of these. The standard duration of adjuvant endocrine treatment has been 5 years for a long time. Nevertheless, the high number of recurrences occurring after 5 years suggested that extended endocrine therapy could further improve outcome, which led to the start of several randomized clinical trials investigating the effects of extended use of endocrine therapy. The extended duration of tamoxifen has been shown to improve disease-free survival and overall survival in the ATLAS and aTTom trials. However, in postmenopausal women, AIs have been shown to be more effective when compared with tamoxifen. Based hereon, it is recommended that adjuvant endocrine therapy in postmenopausal women with early breast cancer should include an AI. Recently, the DATA, IDEAL, and NSABP B42 trials showed that extended adjuvant endocrine therapy with AIs beyond 5 years in postmenopausal women with early breast cancer did reduce the occurrence of secondary breast tumors, but had no or only a small impact on distant metastasis free survival. Furthermore, toxicity of adjuvant AIs led to gradually decreasing compliance rates and long-term toxicities to non-breast cancer-related deaths. Therefore, we suggest considering extended adjuvant treatment only in women with high-risk early breast cancer who tolerate treatment well. 


\section{Introduction}

For years, tamoxifen has been the standard adjuvant endocrine treatment of hormone receptor-positive breast cancer in both pre- and postmenopausal women. In the past decade, several other treatment regimens have been developed, using tamoxifen, aromatase inhibitors (AIs), or a combination of these.

The latest ASCO guideline regarding adjuvant endocrine therapy provides clear recommendations on extended tamoxifen treatment for premenopausal women with hormone receptor-positive early breast cancer [1]. However, for postmenopausal patients, a choice remains between four different treatment regimens; AI monotherapy for 5 years, sequenced treatment with tamoxifen and AIs for 5 years, extended tamoxifen monotherapy for 10 years, or tamoxifen followed by extended AIs for 10 years. To determine which 5-year schedule showed the highest efficacy, the Early Breast Cancer Trialist's Cooperative Group (EBCTCG) has compared three treatment strategies in the adjuvant setting of early breast cancer in postmenopausal women: continuous AI versus tamoxifen monotherapy, sequential tamoxifen and AI versus tamoxifen monotherapy, and sequential tamoxifen

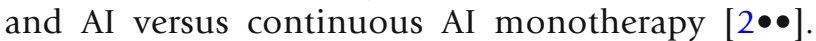
Their meta-analysis showed that 5-year adjuvant endocrine treatment including AIs was more effective than tamoxifen monotherapy in preventing recurrence and breast cancer death in either continuous or sequential regimens.

Recently, a number of trials have been published where the efficacy and tolerability of extended endocrine therapy with AIs beyond 5 years were studied $[3 \bullet 4 \bullet, 5 \bullet, 6 \bullet]$. In this present review, we aim to summarize published randomized controlled trials on the efficacy and tolerability of different regimens of adjuvant endocrine therapy in postmenopausal women with hormone receptor-positive early breast cancer. In particular, the available evidence in terms of efficacy and tolerability of extended adjuvant endocrine treatment beyond 5 years. Moreover, we discuss potential difficulties and consequences of extending endocrine treatment in daily practice in subgroups of postmenopausal women with early breast cancer.

\section{Methods}

A detailed search strategy was used to search the PubMed database, consisting of numerous MeSH heading and text word combinations, "breast cancer," "endocrine therapy," "tamoxifen," "aromatase inhibitors," "exemestane," "anastrozole," "letrozole," "adjuvant," "extended," and "postmenopausal." Publications of randomized clinical phase III trials published before December 2017 in English language were included in our analysis. Abstracts of the yearly conferences of the San Antonio Breast Cancer Symposium (SABCS) and the American Society of Clinical Oncology (ASCO) were searched for relevant trials (and substituted by full papers if published before December 2017). Furthermore, we scanned the references of relevant trials, existing meta-analyses and guidelines for additional important trials. We categorized the studies by treatment regimen (tamoxifen, AI, or sequential) and duration (up to 5 years or more than 5 years). Studies concerning locally advanced and/ or metastatic disease were excluded.

Hazard ratios (HR) were used to assess the treatment effects in each trial. If available, the HRs were directly obtained from the published article or conference presentation. If the trials did not provide HRs, they were calculated using the available methods of Tierney and colleagues [7]. When the results of the included trials were published at multiple 
points in time, the results with the longest follow-up duration were included.

\section{Efficacy of treatment up to 5 years}

The first randomized trials of adjuvant endocrine treatment for early breast cancer started in the mid-1970s and compared 1 to 2 years of tamoxifen with no endocrine treatment showing a reduction in breast cancer recurrences in the tamoxifen treatment groups [8-10]. The observation that these recurrences seemed to occur mostly after the adjuvant treatment period, with a median follow-up of 44-66 months, led to the hypothesis that a longer duration of treatment would further improve outcome.

In the early 1980 s, a multicenter randomized trial demonstrated the superiority of 5 years of adjuvant tamoxifen over 2 years in the treatment of postmenopausal women with hormone receptor-positive early breast cancer [11]. This additional benefit in terms of breast cancer recurrence and mortality was confirmed by later trials and meta-analyses [12-14].

Later on, AIs were developed, offering an alternative strategy to tamoxifen in the adjuvant treatment of postmenopausal women with hormone receptor-positive early breast cancer by preventing the production of endogenous oestrogens. The ATAC trial and the BIG 1-98 trial were the first large trials comparing adjuvant AIs with tamoxifen each for a duration of 5 years in postmenopausal women $[15,16]$. Anastrozole was used in the ATAC trial and letrozole in the BIG 1-98 trial. AIs were found to be superior to tamoxifen in terms of disease-free survival (DFS), recurrencefree survival (RFS), and overall survival (OS).

Thereafter, several studies were performed to investigate the effect of sequenced treatment, using different approaches, but all comparing with 5 years of tamoxifen [17-21]. The ABCSG-8 trial randomized patients between sequential tamoxifen followed by AIs or continuous tamoxifen therapy immediately after the primary breast cancer treatment (surgery, chemotherapy, and/or radiation therapy) and showed a statistically significant improvement in DFS for patients treated with AIs (HR 0.78 (95\% CI 0.60-1.00)). Moreover, OS improved, although not statistically significant (HR 0.87 (95\% CI 0.64-1.16)) [22]. Other trials randomized patients after the initial treatment with tamoxifen, thus selecting a subpopulation of patients with possibly better prognosis and higher endocrine sensitivity [18-21]. Study findings should therefore be interpreted with caution. With the exception of the Japanese NSAS BC03 trial, all trials showed a statistically significant improvement in terms of DFS for sequential endocrine therapy in comparison with 5 years of tamoxifen. After a median followup varying between 30 and 128 months, all trials showed an improved OS, but these results were only statistically significant in the IES and ITA trials.

In addition, both the BIG 1-98 and the TEAM trial addressed the switch to an AI after 2-3 years of tamoxifen in comparison with AI monotherapy for a total of 5 years $[16,17,23 \bullet]$. These trials randomized patients directly after primary breast cancer treatment (surgery, radiation therapy, and/or chemotherapy). Neither study showed a preference for either strategy after a median follow-up of 8.1 and 9.8 years, respectively. This was in line with the intention-to-treat 
patient-level meta-analysis by the EBCTCG showing that both continuous and sequential regimens including AIs are more effective than tamoxifen monother-

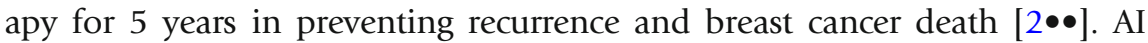
monotherapy was associated with a significant $30 \%$ reduction in recurrences during the first year of endocrine treatment, when compared with a sequential regimen with tamoxifen followed by an AI. In the years thereafter, the number of recurrences did not differ between the treatment groups. Since it is expected that this benefit during the first year of endocrine therapy will not disappear, it is likely that, with longer follow-up, this benefit will also show in DFS and OS outcomes.

\section{Efficacy of extended treatment duration}

Hormone receptor-positive breast cancer is characterized by a very long natural history. As a consequence, some women remain at risk of late recurrence for years, fueling the discussion to prolong endocrine therapy beyond 5 years. The risk of breast cancer recurrence after 5 years of endocrine therapy was evaluated

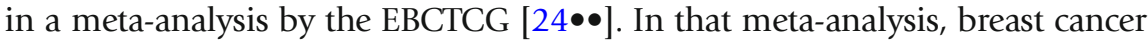
recurrences occurred at a steady rate throughout the study period from 5 to 20 years, strongly correlated with the original tumor- and nodal status and tumor grade. Among the patients with stage T1 disease, the risk of distant recurrence in the period from 5 to 20 years was 13\% without nodal involvement (T1N0), 20\% with N1-3 status, and 34\% with N4-9 status; among those with stage $\mathrm{T} 2$ disease, the risks were $19 \%$ with T2N0, $26 \%$ with T2N1-3, and $41 \%$ with T2N4-9. The risk of death from breast cancer was similarly dependent on TN status.

Other studies reported an annual rate of distant relapse in excess of $2 \%$ for at least 15 years after diagnosis, even after 5 years of tamoxifen [25]. A similar risk remains for at least 10 years for postmenopausal women who have received AIs for 5 years [15]. The Oxford overview analyses likewise show that at least 50\% of recurrences occurred more than 5 years after diagnosis [13]. To determine whether there is any outcome advantage in continuing adjuvant endocrine therapy for more than 5 years, and what the optimal duration of adjuvant endocrine treatment is, several strategies have been researched. These trial findings are summarized in Table 1 and are discussed next.

\section{Extended tamoxifen monotherapy}

Results from the recent large ATLAS and aTTom trials clearly demonstrated that 10 years of tamoxifen showed an improved RFS and OS in comparison with 5 years of tamoxifen treatment (no data about DFS available) [26-28]. Also, the smaller ECOG trial showed a benefit for 10 years tamoxifen treatment [29]. In contrast, data from the NSABP B-14 trial and the Scottish trial failed to demonstrate a positive impact of prolonged tamoxifen treatment on RFS and OS [30,31].

\section{Extended sequential regimen}

Additionally, there have been studies investigating the use of AIs after 5 years of tamoxifen treatment. The ABCSG-6a, MA.17 and NSABP B33 trials all showed a 
Table 1. Overview of the reported results considering efficacy in the published trials on extended adjuvant endocrine treatment in postmenopausal women with early stage breast cancer

\begin{tabular}{|c|c|c|c|c|c|c|c|c|c|c|c|c|c|c|c|c|c|c|c|c|}
\hline Trial & $\begin{array}{l}\text { Samp } \\
\text { le } \\
\text { size }\end{array}$ & $\begin{array}{l}\text { Medi } \\
\text { an } \\
\text { FU } \\
\text { (yrs) }\end{array}$ & $\begin{array}{l}\text { Treat } \\
\text { ment } \\
\text { arm }\end{array}$ & $\begin{array}{r}\text { Yrs } \\
1\end{array}$ & 2 & 3 & 4 & 5 & 6 & 7 & 8 & 9 & 10 & 11 & 12 & 13 & 14 & 15 & $\begin{array}{l}\text { DFS } \\
\text { HR (95\%CI) }\end{array}$ & $\begin{array}{l}\text { OS } \\
\text { HR (95\%CI) }\end{array}$ \\
\hline \multirow[t]{2}{*}{ MA.17[34] } & 5187 & 5.3 & I & & & & & & & & & & & & & & & & $0.68(0.56-0.83)$ & $0.99(0.79-1.24)$ \\
\hline & & & $\mathrm{C}$ & & & & & & & & & & & & & & & & & \\
\hline \multirow[t]{2}{*}{ NSABP B-33[33] } & 1598 & 2.5 & I & & & & & & & & & & & & & & & & $0.68(0.45-1.03)$ & NR \\
\hline & & & $\mathrm{C}$ & & & & & & & & & & & & & & & & & \\
\hline \multirow[t]{2}{*}{ ABCSG 6a[32] } & 856 & 5.2 & I & & & & & & & & & & & & & & & & $0.62(0.40-0.96)^{*}$ & $0.89(0.53-1.34)$ \\
\hline & & & $\mathrm{C}$ & & & & & & & & & & & & & & & & & \\
\hline \multirow[t]{2}{*}{ ATLAS[26] } & 6846 & 7.6 & I & & & & & & & & & & & & & & & & $0.84(0.76-.93) *$ & $0.87(0.78-0.97)$ \\
\hline & & & $\mathrm{C}$ & & & & & & & & & & & & & & & & & \\
\hline \multirow[t]{2}{*}{ aTTom[28,27] } & 6953 & $\sim 9.0$ & I & & & & & & & & & & & & & & & & $0.86(0.77-0.96)^{*}$ & $0.94(0.86-1.03)$ \\
\hline & & & $\mathrm{C}$ & & & & & & & & & & & & & & & & & \\
\hline \multirow[t]{2}{*}{ MA.17R[6] } & 1918 & 6.3 & I & & & & & & & & & & & & & & & & $0.80(0.63-1.01)$ & $0.97(0.73-1.28)$ \\
\hline & & & $\mathrm{C}$ & & & & & & & & & & & & & & & & & \\
\hline \multirow[t]{2}{*}{ DATA[3] } & 1660 & 4.4 & I & & & & & & & & & & & & & & & & $0.79(0.62-1.02)$ & $0.91(0.65-1.29)$ \\
\hline & & & $\mathrm{C}$ & & & & & & & & & & & & & & & & & \\
\hline \multirow[t]{2}{*}{ IDEAL[4] } & 1824 & 6.6 & I & & & & & 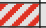 & & & & & & & & & & & $0.92(0.74-1.16)$ & $1.04(0.78-1.38)$ \\
\hline & & & $\mathrm{C}$ & & & & & & & & & & & & & & & & & \\
\hline \multirow[t]{2}{*}{ NSABP B-42[5] } & 3966 & 6.9 & I & & & & & & & & & & & & & & & & $0.85(0.73-0.99)$ & $1.15(0.92-1.44)$ \\
\hline & & & $\mathrm{C}$ & & & & & & & & & & & & & & & & & \\
\hline \multirow[t]{2}{*}{ SOLE[36] } & 4884 & 5.0 & I & 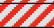 & & & 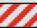 & 2 & \multicolumn{5}{|c|}{ Intermittent 9 months per year } & & & & & & $1.08(0.93-1.26)$ & $0.85(0.68-1.06)$ \\
\hline & & & $\mathrm{C}$ & 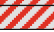 & & & & 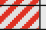 & & & inuo & & & & & & & & & \\
\hline
\end{tabular}

Red: tamoxifen. Gray: aromatase inhibitor. Diagonal lines: either tamoxifen or an aromatase inhibitor.

FU follow-up, I intervention arm, C control arm, yrs. years, DFS disease-free survival, HR hazard ratio, CI confidence interval, OS overall survival *No data on DFS available, data on RFS reported

clear benefit of 5 years AI treatment after an initial 5 years of tamoxifen in DFS [32-34]. There was also an improvement in OS, but this was not statistically significant. This may have been caused by a lack of power due to early unblinding of the study. The early interim analysis of the MA.17 trial, after a median of 2.5 years of follow-up, showed an improved DFS for women using letrozole after 5 years of tamoxifen (HR 0.58 (95\% CI 0.45-0.76)). After unblinding, $60 \%$ of placebo patients crossed over to letrozole, which complicated the efficacy analysis. Due to the results of the MA.17 interim analysis, also the NSABP B33 trial was unblinded early after a median follow-up of 2.5 years.

Several studies investigated the efficacy and safety of additional treatment with AIs after a sequential regimen of tamoxifen and an AI for 5 years $[3 \bullet, 4 \bullet$, $5 \bullet$. The DATA trial investigated the effectiveness of 6 versus 3 years of anastrozole after an initial 2-3 year of tamoxifen in patients who were disease-free 3 years after randomization [3•]. The 5-year adapted DFS was not statistical significantly better for the overall study population in the 6-year group (HR 0.79 (95\% CI 0.62-1.02); $p=0.066$ ). However, in the subgroup of women with high-risk tumors, extended endocrine therapy was associated with an improved adapted DFS. For instance, in women with node positive disease, 5 -year DFS was $84 \%$ in the 6-year group versus $76 \%$ in the 3 -year group (HR 0.64 (95\% CI $0.46-0.89), p=0.0075)$; and $83 \%$ versus $69 \%$ if also having a larger tumor size ( $\geq$ T2; HR 0.53 (95\% CI 0.53-0.82), $p=0.0031$ ). Nevertheless, great care must be taken when interpreting subgroup analyses and should be interpreted as hypothesis generating rather than definitive. The results of a similar trial (GIM-4-LEAD; NCT01064635) are awaited, studying the effect of letrozole for 2-3 years versus 5 years after an initial 2-3 years of tamoxifen.

The IDEAL trial investigated the use of 2.5 versus 5 years of letrozole after an initial 5 years of endocrine treatment [ $4 \bullet$. The initial treatment could either be tamoxifen monotherapy, AI monotherapy, or a sequential regimen. Regardless 
of the initial treatment regimen, no statistically significant benefit on DFS and OS was found for 5 years of extended letrozole treatment in comparison to an extended 2.5 years of AI treatment.

The NSABP B42 study investigated the efficacy of 5 years of letrozole after an initial 5 -year of endocrine therapy including an $\mathrm{AI}[5 \bullet]$. This could be either AI monotherapy, or sequenced with tamoxifen. In the overall analysis, no statistically significant benefit was found for extended letrozole on DFS and OS. However, the results for distant recurrence-free survival (DRFS) and breast cancer-free interval (BCFI) were statistically significantly better for the extended treatment group (DRFS: HR 0.72 (95\% CI 0.53-0.97), $p=0.03$; BCFI: HR 0.71 (95\% CI 0.56-0.89), $p=0.003$ ).

The MA.17R trial investigated the efficacy of 5 years of letrozole after an initial 10-year treatment with tamoxifen for 5 years followed by AI for 5 years [6•]. The 5-year DFS rate was 95\% with letrozole and $91 \%$ with placebo (HR 0.80 (95\% CI $0.63-1.01), p=0.06)$. The rate of 5 -year OS was not different (93 versus 94\% for the letrozole and placebo groups respectively). The annual incidence rate of contralateral breast cancer in the letrozole group was $0.21 \%$, and the rate in the placebo group was $0.49 \%$ (HR 0.42 (95\% CI $0.22-0.81), p=0.007$ ). This suggests that the benefit of extended endocrine therapy in this trial was mainly caused by a reduction in the development of contralateral breast cancer.

In a recent meta-analysis on extended endocrine therapy, including the abovementioned trials, particularly women with a positive nodal status seemed to have more benefit of extended endocrine therapy (node positive HR 0.72 versus node negative HR 0.83) [35•]. Similarly, a relative larger benefit was seen from extended endocrine therapy in women with a larger tumor size $(>2 \mathrm{~cm}$ HR 0.77 versus $\leq 2 \mathrm{~cm}$ HR 0.88 ), and for those with both ER and PR expression versus single receptor expression (HR 0.68 versus 1.01 ). A greater effect was also seen in patients who received adjuvant chemotherapy compared with those who did not (HR 0.71 versus 0.80 ). However, as exposure to chemotherapy is probably a surrogate measure for worse disease, this finding could be a reflection of higher chemotherapy receipt among patients with larger tumors and/or nodal involvement. Even though the differences in effect size of AIs between the higher and lower risk groups were not statistically different, it is yet an intriguing observation as in contrast to these AI studies, extended tamoxifen yielded similar relative benefits for the prognostic subgroups [26].

Another treatment approach was tested in the SOLE trial, in which it was hypothesized that resistance to letrozole could be reversed by withdrawal and reintroduction of letrozole [36•]. Postmenopausal women, previously treated by 5 years of endocrine treatment (tamoxifen, AI, or sequential), were randomized to either 5 years of intermittent letrozole or 5 years of continuous letrozole. Intermittent letrozole use did not improve DFS compared with continuous letrozole use (HR 1.08 (95\% CI 0.93-1.26)).

\section{Compliance}

Compliance is an important issue in adjuvant endocrine therapy in general because it influences the efficacy. A recent analysis of the BIG 1-98 trial looked at treatment adherence and its impact on DFS in patients on tamoxifen, 
letrozole, or a sequential regimen for 5 years [37]. Both early cessation and a low compliance score were associated with a reduced DFS. Sequential treatments were associated with higher rates of non-persistence (Tam-Let, 20.8\%; Let-Tam, 20.3\%; Tam $16.9 \%$; Let $17.6 \%$ ). In $82.7 \%$ of patients, adverse events were the reason for discontinuation. The reason sequential endocrine therapy with tamoxifen and AIs could be preferred over AI monotherapy is diverse. Costs, due to patency, used to play a restricting role in the use of AIs. Nowadays, adverse events like musculoskeletal events and bone loss are frequently the motivation for switching therapies [38, 39]. Furthermore, Henry and colleagues reported a $32 \%$ discontinuation rate for initial AI therapy within 2 years due to adverse events; $24 \%$ of the total study population discontinued specifically because of musculoskeletal symptoms [40]. The high percentage of discontinuation in the women taking tamoxifen might be explained by a younger age. A large cohort study published by Hershman and colleagues reported that women aged under 40 years had the highest risk of discontinuation in comparison with older aged women (HR 1.51 (95\% CI 1.23-1.85) [41]. Also, two other studies showed a younger age to be a predictor of premature discontinuation of tamoxifen $[42,43]$.

For both tamoxifen and AIs, the probability of early termination increases with a longer treatment duration. A systematic, qualitative meta-regression analysis illustrated endocrine treatment discontinuation rates ranging from 31 to $73 \%$ over the treatment period [44]. In the women taking tamoxifen, $13.6 \%$ discontinued during the first year of treatment, which increased to $47.1 \%$ at 5 years. In the women taking AIs, percentages of discontinuation were $11.7 \%$ during the first year and $31.3 \%$ at 5 years $[44,45]$. Likewise, another study described increasing discontinuation rates each year of AI treatment, ranging from 14 to $22 \%$ in the first year to $21-38 \%$ in the third year [42]. Early discontinuation rates in the published trials investigating extended endocrine therapy are as high as $30 \%[3 \bullet, 4 \bullet 5 \bullet, 37]$.

Each type of endocrine therapy is known for its drug-specific side effects. Tamoxifen inhibits the growth of breast tumors by competitive antagonism of estrogen at its receptor site. Its actions are complex and it also has partial estrogen agonist effects. These partial agonist effects can be beneficial, since they may help prevent bone demineralization in postmenopausal women, but also unfavorable, as they are associated with increased risks of uterine cancer and thromboembolism [38].

AIs suppress plasma and intra-tumoral estrogen concentrations in postmenopausal women by inhibiting or inactivating aromatase: the enzyme responsible for synthesizing oestrogens from androgenic substrate [46]. Unlike tamoxifen, AIs have no partial agonist activity. AIs have side effects that are predominantly predictable consequences of estrogen deprivation [38]. Musculoskeletal events (e.g. arthralgia and myalgia), bone loss and cardiovascular events have been reported frequently during AI use [39]. In contrast to tamoxifen, follow-up of the adjuvant AI trials is relatively short- and the long-term consequences of adjuvant AI use have yet to be fully determined. 
A meta-analysis including seven trials comprising 16,349 patients analyzed the reported toxicity of extended endocrine treatment with AIs [47•]. Longer treatment with AIs was associated with increased odds of cardiovascular events (odds ratio $(\mathrm{OR})=1.18, p=0.05$, number needed to harm $(\mathrm{NNH})=122)$, bone fractures $(\mathrm{OR}=1.34, p<.001, \mathrm{NNH}=72)$, and cessation of treatment due to adverse events $(\mathrm{OR}=1.45, p<0.001, \mathrm{NNH}=21)$. Extended use of AIs did not influence the odds of a second malignancy $(\mathrm{OR}=0.93, p=0.56)$, but a numerical excess of deaths without breast cancer recurrence was found with prolonged AI $(\mathrm{OR}=1.11, p=0.34)$. Even though the increase of deaths without breast cancer recurrence was not statistically significant, this might change when future results of these trials with a longer follow-up duration are published. The updated results of the TEAM trial, comparing 5 years of anastrozole with a 5year sequenced regimen with tamoxifen and anastrozole with a median followup of 9.8 years, showed that the potential beneficial effect of exemestane on breast cancer-specific mortality might be counterbalanced by an increase in non-breast cancer-related mortality ( 12 versus $10 \%$ ), leading to a similar overall survival between the treatment groups [23•].

\section{Postmenopausal due to prior chemotherapy}

AIs are contraindicated in premenopausal women. Noteworthy, AIs are also contraindicated in women with chemotherapy-induced ovarian function failure because of the possibility of ovarian function recovery [48, 49]. Therefore, we advise against using AIs in women with chemotherapy-induced ovarian function failure, and also advise caution even when used in combination with gonadotropinreleasing hormone (GnRH) agonists. GnRH agonists do not suppress the ovarian function completely in all patients, as was observed in the SOFT-EST trial [50]. During 12 months of follow-up, $34.2 \%$ of the patients had inadequately suppressed E2 levels, at least once, indicating incomplete ovarian function suppression [50]. This might be the underlying reason that the combination of $\mathrm{AI} / \mathrm{GnRH}$ agonist has not shown to improve overall survival in comparison with tamoxifen monotherapy or the combination of tamoxifen/GnRH [51, 52]. Hence, for women who became postmenopausal due to prior chemotherapy, extended adjuvant endocrine treatment with tamoxifen can be used in case of high-risk tumors.

\section{Future perspectives}

Future research needs to identify the subgroup of women that will have benefit of extended endocrine treatment. In designing a therapeutic strategy to prevent disease recurrence, it is necessary to not only have knowledge about the total risk of relapse but also to ascertain when recurrence is most likely to occur and when this risk becomes minimal. For this purpose, annual hazard rates could be used. Annual hazard rates describe the changes in the risk of recurrence over time. Instead of simply estimating the overall course of disease, they emphasize when a relapse occurs. When looking at the annual hazard rate curves of women with hormone receptor-positive breast cancer, it comes across that recurrences occur even more than 10 years after the initial diagnosis. Dignam and colleagues 


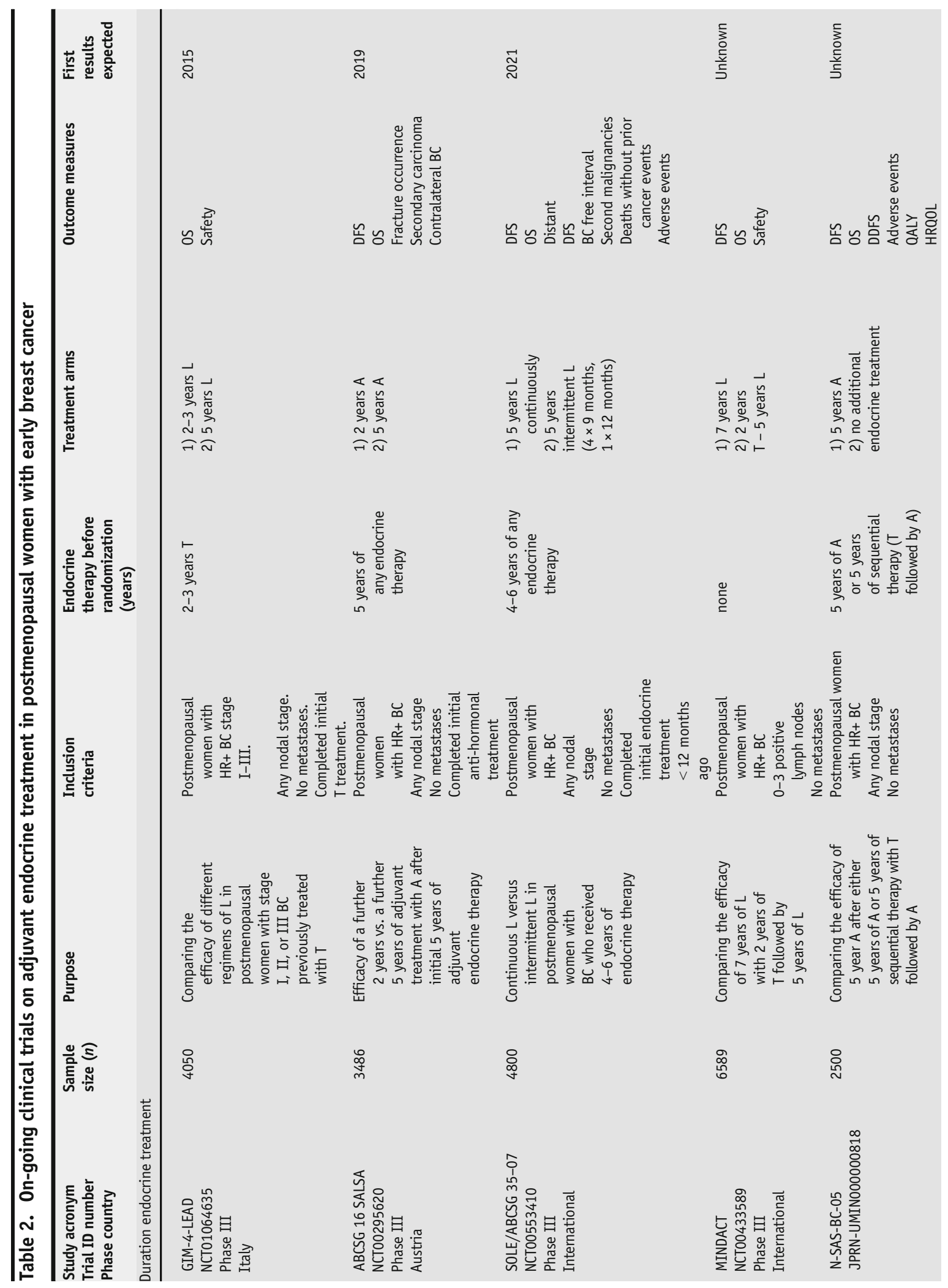




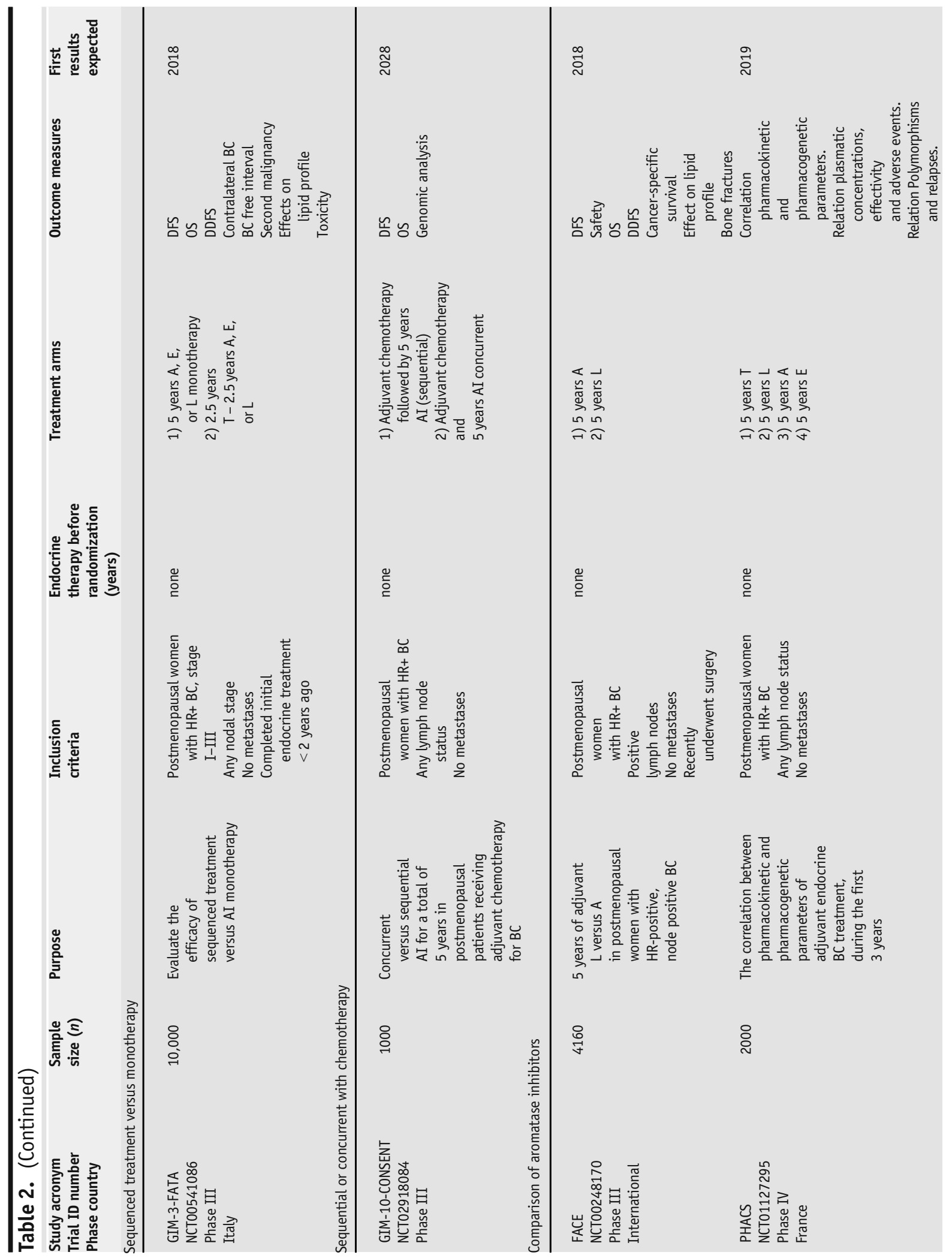




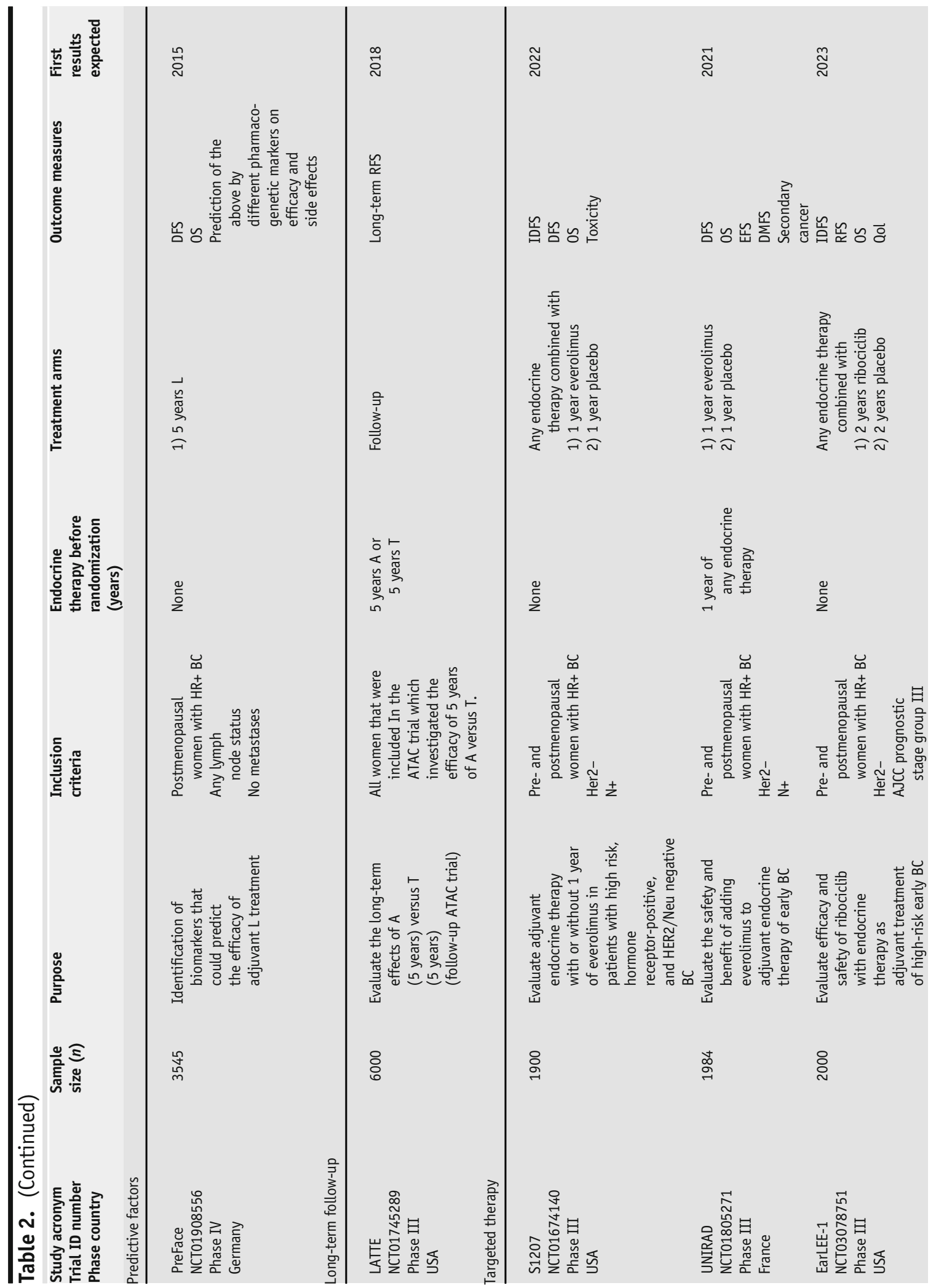




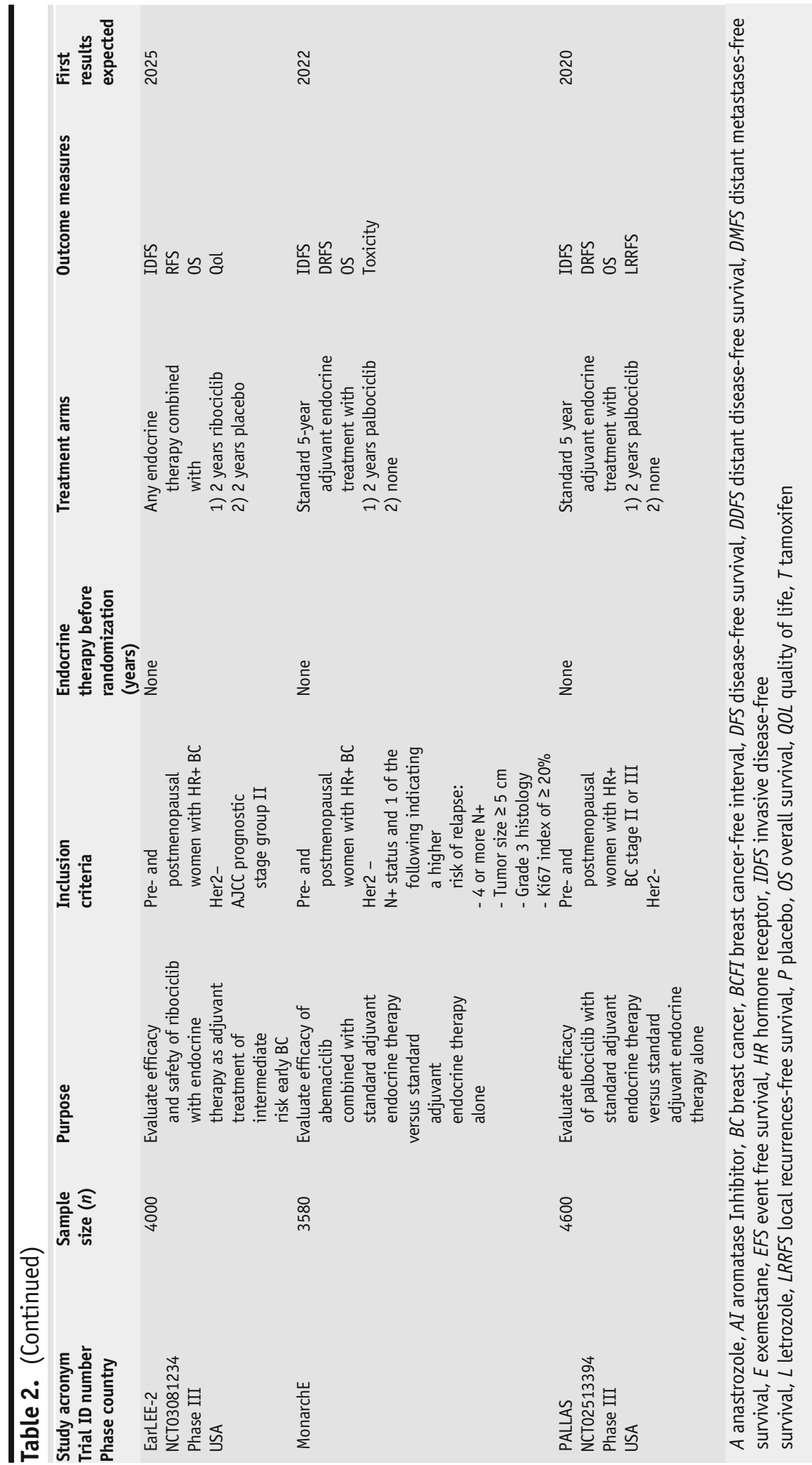




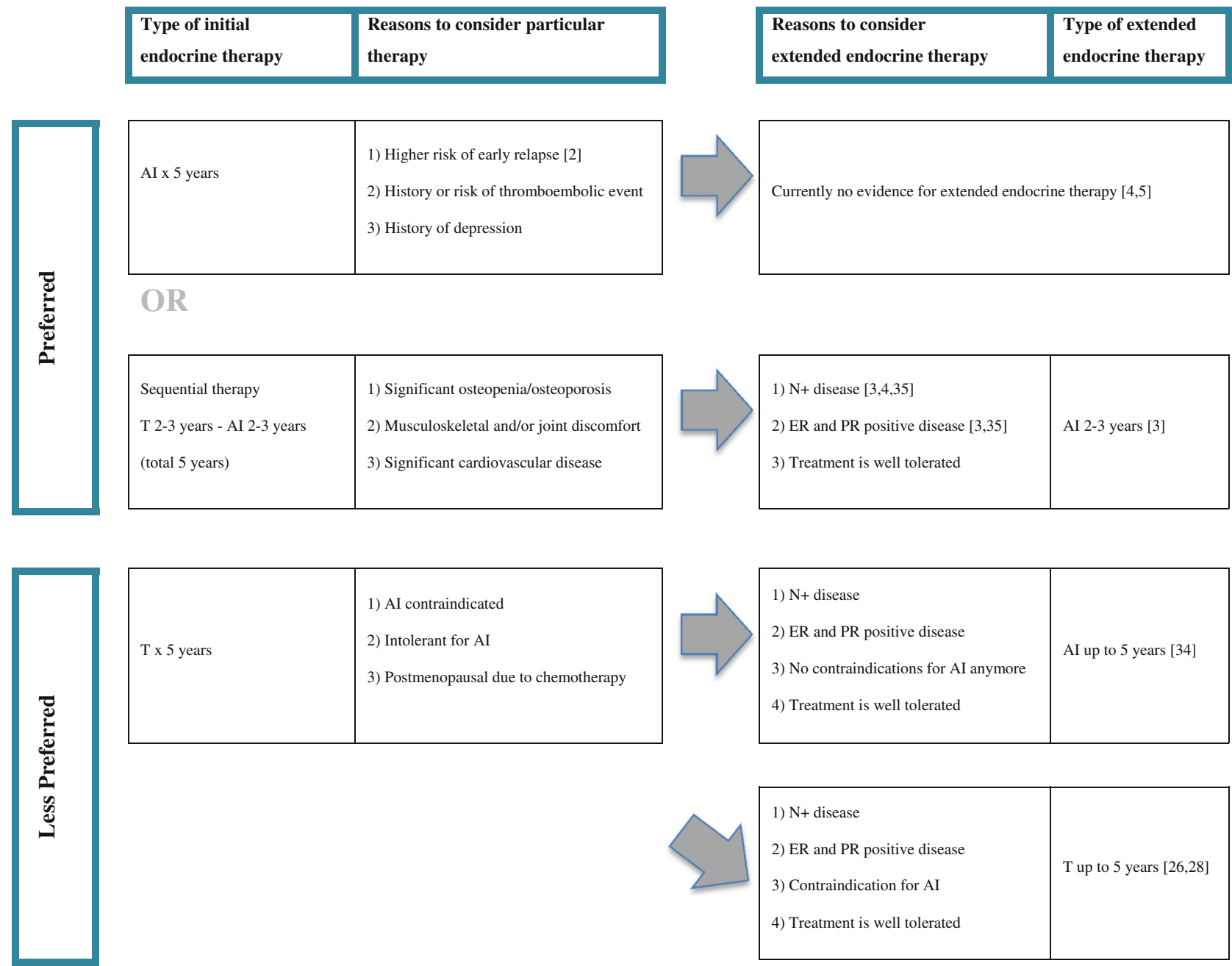

Fig. 1. Adjuvant endocrine treatment in postmenopausal women with early stage hormone receptor-positive breast cancer. AI, aromatase inhibitor; $T$, tamoxifen.

presented the annual recurrence hazard for women with node negative early breast cancer that had undergone surgery without subsequent systemic adjuvant treatment [53]. The annual hazard rate for patients with hormone receptor negative tumors reached a peak around 18 months and diminished rapidly afterwards. In the hormone receptor-positive group, this peak appeared slightly later but had a less rapid decrease and did not diminish totally during a follow-up of 12 years. Considering an annual risk of distant recurrence remains $1-2 \%$ for at least $15-20$ years after diagnosis of hormone receptor-positive breast cancer, even after 5 years of endocrine therapy, extended adjuvant therapy may seem a logical approach $[24 \bullet \bullet]$. However, from the trials on extended adjuvant endocrine therapy, it is suggested that these have in general a larger impact on secondary breast cancers and loco-regional recurrences than on distant 
recurrences. Moreover, it is debated whether the effect size might be larger for extended adjuvant endocrine therapy in those who received initially tamoxifen than in those who received initially AIs. Hence, extending endocrine therapy seems not to be the solution for the observed late distant recurrences.

Moreover, many women are treated with endocrine agents who will never develop metastases. Consequently, they unnecessarily suffer from side effects that influence their quality of life. Therefore, it is important to identify those women with a high risk of relapse and who will have maximum benefit from extended endocrine treatment. For this purpose, several strategies could be used. Firstly, clinical studies investigating endocrine therapy should divide women with hormone receptor-positive breast cancer in luminal A and luminal B subgroups. Luminal B breast cancer has been reported to have lower expression of hormone receptors, higher expression of proliferation markers, and higher histologic grade than luminal A, all exhibiting to a worse prognosis [54]. Furthermore, luminal B breast cancer has a distinct profile of response to endocrine therapy and chemotherapy [54].

The use of several molecular risk scores was approved for use in decision-making concerning adjuvant chemotherapy, however, if these scores can also be used to guide decisions on extended endocrine therapy is not sufficiently clear yet [55]. Nevertheless, the TransATAC trial showed promising results in predicting which women had a low risk of developing distant recurrences 5 to 10 years after breast cancer diagnosis, thereby identifying the women in who extended therapy is not justified [56,57].

Furthermore, several studies are now combining endocrine therapy with a targeted drug, such as mTOR inhibition or CDK $4 / 6$ inhibition. Much is expected from these combinations, although toxicity is like significantly worse which again can compromise compliance and indirectly efficacy. For that reasons, most studies have chosen to select only high-risk patients based on tumor size, nodal status, and/or histological grade. The on-going trials on the adjuvant endocrine treatment in postmenopausal women with early breast cancer are presented in Table 2 .

\section{Conclusions}

Based on the reviewed literature, we believe both the type and duration of adjuvant endocrine treatment should be personalized based on expected efficacy and tolerability. The identification of subgroups of patients who might benefit from extended endocrine treatment is of great significance. Possibly molecular risk scores will offer more insight hereon in the future. Moreover, it is important to consider quality of life during treatment and other long-term toxicities, such as osteoporosis and cardiovascular diseases that might interfere with overall survival outcome. If a patient tolerates the endocrine treatment well, extended use of hormonal therapy, especially if not initially treated with AIs, could be considered in case of a high-risk tumor that is both ER and PR positive (Fig. 1). But, more targeted treatment approaches are eagerly awaited for from on-going trials. 


\section{Compliance with Ethical Standards}

\section{Conflict of Interest}

Irene E.G. van Hellemond has received research funding through a grant to her institution from AstraZeneca for the DATA study, and has received reimbursement for travel expenses from Roche.

Sandra M.E. Geurts has received research funding through grants to her institution from Novartis BV, Roche, and Pfizer.

Vivianne C.G. Tjan-Heijnen has received research funding through grants to her institution from Eisai, Roche, Pfizer, Novartis, and AstraZeneca; has received compensation from AstraZeneca, Pfizer, Novartis, and Roche for service as a consultant; has received honoraria from Pfizer, Roche, and Novartis; and has received reimbursement for travel expenses from Pfizer, Novartis, and Roche.

\section{Human and Animal Rights and Informed Consent}

All reported studies/experiments with human or animal subjects performed by the authors have been previously published and complied with all applicable ethical standards (including the Helsinki declaration and its amendments, institutional/national research committee standards, and international/national/institutional guidelines).

\section{Open Access}

This article is distributed under the terms of the Creative Commons Attribution 4.0 International License (http://creativecommons.org/licenses/by/4.0/), which permits unrestricted use, distribution, and reproduction in any medium, provided you give appropriate credit to the original author(s) and the source, provide a link to the Creative Commons license, and indicate if changes were made.

\section{References and Recommended Reading}

Papers of particular interest, published recently, have been highlighted as:

- Of importance

$\bullet \quad$ Of major importance

1. Burstein HJ, Temin S, Anderson H, Buchholz TA, Davidson NE, Gelmon KE, et al. Adjuvant endocrine therapy for women with hormone receptorpositive breast cancer: american society of clinical oncology clinical practice guideline focused update. J Clin Oncol. 2014;32(21):2255-69.

2.• Early Breast Cancer Trialists' Collaborative G, Dowsett M, Forbes JF, Bradley R, Ingle J, Aihara T, et al. Aromatase inhibitors versus tamoxifen in early breast cancer: patient-level meta-analysis of the randomised trials. Lancet. 2015;386(10001):1341-52.

Important patient-level meta-analysis comparing several strategies of 5-year adjuvant endocrine therapy.

3. Tjan-Heijnen VCG, van Hellemond IEG, Peer PGM, Swinkels ACP, Smorenburg CH, van der Sangen MJC, Kroep JR, De Graaf H, Honkoop AH, Erdkamp FLG, van den Berkmortel F, de Boer M, de Roos WK, Linn SC, Imholz ALT, Seynaeve CM, Dutch Breast Cancer
Research Group for the DI (2017) Extended adjuvant aromatase inhibition after sequential endocrine therapy (DATA): a randomised, phase 3 trial. Lancet Oncol 18 (11):1502-1511.

Trial on extended adjuvant aromatase inhibitor therapy.

4. Blok EJ, Kroep JR, Meershoek-Klein Kranenbarg E, Duijm-de Carpentier M, Putter H, van den Bosch J, Maartense E, van Leeuwen-Stok AE, Liefers GJ, Nortier JWR, Rutgers EJT, van de Velde CJH, Group IS (2018) Optimal Duration of Extended Adjuvant Endocrine Therapy for Early Breast Cancer; Results of the IDEAL Trial (BOOG 2006-05). J Natl Cancer Inst 110 (1). Trial on extended adjuvant aromatase inhibitor therapy.

5. Mamounas EP, Bandos H, Lembersky BC, Geyer JCE, Fehrenbacher L, Graham ML, Chia SL, Brufsky AM, Hennessy BT, Soori GS, Dakil SR, Seay TE, Wade IJL, McCarron EC, Paik S, Swain SM, Wickerham DL, Wolmark N A Randomized, double-blinded, placebo- 
controlled clinical trial of extended adjuvant endocrine therapy (tx) with letrozole (L) in postmenopausal women with hormone-receptor (+) breast cancer (BC) who have completed previous adjuvant tx with an aromatase inhibitor (AI): results from NRG Oncology/ NSABP B-42. In: Presented at: 2016 San Antonio Breast Cancer Symposium; December 6-10; San Antonio, TX, 2016.

Trial on extended adjuvant aromatase inhibitor therapy.

6. $\quad$ Goss PE, Ingle JN, Pritchard KI, Robert NJ, Muss H, Gralow J, et al. Extending aromatase-inhibitor adjuvant therapy to 10 years. $\mathrm{N}$ Engl J Med. 2016;375(3):209-19.

Trial on extended adjuvant aromatase inhibitor therapy.

7. Tierney JF, Stewart LA, Ghersi D, Burdett S, Sydes MR. Practical methods for incorporating summary time-to-event data into meta-analysis. Trials. 2007;8:16.

8. Controlled trial of tamoxifen as adjuvant agent in management of early breast cancer. Interim analysis at four years by Nolvadex Adjuvant Trial Organisation. Lancet.1983;1(8319):257-261.

9. Controlled trial of tamoxifen as a single adjuvant agent in the management of early breast cancer. Br J Cancer. 1988;57(6):608-611.

10. Cyclophosphamide and tamoxifen as adjuvant therapies in the management of breast cancer. Br J Cancer. 1988;57(6):604-607.

11. Randomized trial of two versus five years of adjuvant tamoxifen for postmenopausal early stage breast cancer. Swedish Breast Cancer Cooperative Group. J Natl Cancer Inst. 1996;88(21):15431549.

12. Early Breast Cancer Trialists' Collaborative G. Effects of chemotherapy and hormonal therapy for early breast cancer on recurrence and 15-year survival: an overview of the randomised trials. Lancet.

2005;365(9472):1687-717.

13. Early Breast Cancer Trialists' Collaborative G, Davies C, Godwin J, Gray R, Clarke M, Cutter D, et al. Relevance of breast cancer hormone receptors and other factors to the efficacy of adjuvant tamoxifen: patient-level meta-analysis of randomised trials. Lancet. 2011;378(9793):77184.

14. Hackshaw A, Roughton M, Forsyth S, Monson K, Reczko K, Sainsbury R, et al. Long-term benefits of 5 years of tamoxifen: 10-year follow-up of a large randomized trial in women at least 50 years of age with early breast cancer. J Clin Oncol. 2011;29(13):165763.

15. Cuzick J, Sestak I, Baum M, Buzdar A, Howell A, Dowsett $M$, et al. Effect of anastrozole and tamoxifen as adjuvant treatment for early-stage breast cancer: 10year analysis of the ATAC trial. Lancet Oncol. 2010;11(12):1135-41.

16. Regan MM, Neven P, Giobbie-Hurder A, Goldhirsch A, Ejlertsen B, Mauriac L, et al. Assessment of letrozole and tamoxifen alone and in sequence for postmenopausal women with steroid hormone receptor-positive breast cancer: the BIG $1-98$ randomised clinical trial at 8.1 years median follow-up. Lancet Oncol. 2011;12(12):1101-8.

17. van de Velde CJ, Rea D, Seynaeve C, Putter $\mathrm{H}$, Hasenburg A, Vannetzel JM, et al. Adjuvant tamoxifen and exemestane in early breast cancer (TEAM): a randomised phase 3 trial. Lancet. 2011;377(9762):321-31.

18. Bliss JM, Kilburn LS, Coleman RE, Forbes JF, Coates AS, Jones SE, et al. Disease-related outcomes with longterm follow-up: an updated analysis of the intergroup exemestane study. J Clin Oncol. 2012;30(7):709-17.

19. Boccardo F, Guglielmini P, Bordonaro R, Fini A, Massidda B, Porpiglia M, et al. Switching to anastrozole versus continued tamoxifen treatment of early breast cancer: long term results of the Italian Tamoxifen Anastrozole trial. Eur J Cancer. 2013;49(7):1546-54.

20. Aihara T, Takatsuka Y, Ohsumi S, Aogi K, Hozumi $\mathrm{Y}$, Imoto $\mathrm{S}$, et al. Phase III randomized adjuvant study of tamoxifen alone versus sequential tamoxifen and anastrozole in Japanese postmenopausal women with hormone-responsive breast cancer: N-SAS BC03 study. Breast Cancer Res Treat. 2010;121(2):379-87.

21. Kaufmann M, Jonat W, Hilfrich J, Eidtmann H, Gademann G, Zuna I, et al. Improved overall survival in postmenopausal women with early breast cancer after anastrozole initiated after treatment with tamoxifen compared with continued tamoxifen: the ARNO 95 Study. J Clin Oncol. 2007;25(19):2664-70.

22. Dubsky PC, Jakesz R, Mlineritsch B, Postlberger S, Samonigg H, Kwasny W, et al. Tamoxifen and anastrozole as a sequencing strategy: a randomized controlled trial in postmenopausal patients with endocrine-responsive early breast cancer from the Austrian Breast and Colorectal Cancer Study Group. J Clin Oncol. 2012;30(7):722-8.

23. Derks MGM, Blok EJ, Seynaeve C, Nortier JWR, Kranenbarg EM, Liefers GJ, et al. Adjuvant tamoxifen and exemestane in women with postmenopausal early breast cancer (TEAM): 10-year follow-up of a multicentre, open-label, randomised, phase 3 trial. Lancet Oncol. 2017;18(9):1211-20.

Trial on adjuvant aromatase inhibitors with a long follow-up.

24.•Pan H, Gray R, Braybrooke J, Davies C, Taylor C, McGale P, et al. 20-year risks of breast-cancer recurrence after stopping endocrine therapy at 5 years. $\mathrm{N}$ Engl J Med. 2017;377(19):1836-46.

Important trial on the annual hazard of breast cancer recurrence after adjuvant endocrine therapy in hormone receptor positive breast cancer.

25. Saphner T, Tormey DC, Gray R. Annual hazard rates of recurrence for breast cancer after primary therapy. J Clin Oncol. 1996;14(10):2738-46.

26. Davies C, Pan H, Godwin J, Gray R, Arriagada R, Raina $\mathrm{V}$, et al. Long-term effects of continuing adjuvant tamoxifen to 10 years versus stopping at 5 years after diagnosis of oestrogen receptor-positive breast cancer: 
ATLAS, a randomised trial. Lancet.

2013;381(9869):805-16.

27. Gray R. aTTom: long-term effects of continuing adjuvant tamoxifen to 10 years versus stopping at 5 years in 6,934 women with early breast cancer. J Clin Oncol. 2008;31((suppl)):abstr 5.

28. Rea DW, Gray RG, Bowden SJ, et al. Overall and subgroup findings of the aTTom trial: a randomised comparison of continuing adjuvant tamoxifen to 10 years compared to stopping after 5 years in 6953 women with ER positive or ER untested early breast cancer. ECC. 2013:1860.

29. Tormey DC, Gray R, Falkson HC. Postchemotherapy adjuvant tamoxifen therapy beyond five years in patients with lymph node-positive breast cancer. Eastern Coop Oncol Group J Natl Cancer Inst. 1996;88(24):1828-33.

30. Stewart HJ, Prescott RJ, Forrest AP. Scottish adjuvant tamoxifen trial: a randomized study updated to 15 years. J Natl Cancer Inst. 2001;93(6):456-62.

31. Fisher B, Dignam J, Bryant J, Wolmark N. Five versus more than five years of tamoxifen for lymph nodenegative breast cancer: updated findings from the $\mathrm{Na}$ tional Surgical Adjuvant Breast and Bowel Project B-14 randomized trial. J Natl Cancer Inst. 2001;93(9):684-90.

32. Jakesz R, Greil R, Gnant M, Schmid M, Kwasny W, Kubista E, et al. Extended adjuvant therapy with anastrozole among postmenopausal breast cancer patients: results from the randomized Austrian Breast and Colorectal Cancer Study Group Trial 6a. J Natl Cancer Inst. 2007;99(24):1845-53.

33. Mamounas EP, Jeong JH, Wickerham DL, Smith RE, Ganz PA, Land SR, et al. Benefit from exemestane as extended adjuvant therapy after 5 years of adjuvant tamoxifen: intention-to-treat analysis of the National Surgical Adjuvant Breast And Bowel Project B-33 trial. J Clin Oncol. 2008;26(12):1965-71.

34. Jin H, Tu D, Zhao N, Shepherd LE, Goss PE. Longerterm outcomes of letrozole versus placebo after 5 years of tamoxifen in the NCIC CTG MA.17 trial: analyses adjusting for treatment crossover. J Clin Oncol. 2012;30(7):718-21.

35. Goldvaser H, AlGorashi I, Ribnikar D, Seruga B, Templeton AJ, Ocana A, et al. Efficacy of extended adjuvant therapy with aromatase inhibitors in early breast cancer among common clinicopathologicallydefined subgroups: a systematic review and metaanalysis. Cancer Treat Rev. 2017;60:53-9.

Meta-analysis on extended adjuvant aromatase inhibitor therapy.

36. Colleoni M, Luo W, Karlsson P, Chirgwin J, Aebi S, Jerusalem G, et al. Extended adjuvant intermittent letrozole versus continuous letrozole in postmenopausal women with breast cancer (SOLE): a multicentre, open-label, randomised, phase 3 trial. Lancet Oncol. 2018;19(1):127-38.

Trial on extended adjuvant aromatase inhibitor therapy.
37. Chirgwin JH, Giobbie-Hurder A, Coates AS, Price KN, Ejlertsen B, Debled M, et al. Treatment adherence and its impact on disease-free survival in the Breast International Group 1-98 trial of tamoxifen and letrozole, alone and in sequence. J Clin Oncol. 2016;34(21):2452-9.

38. Perez EA. Safety profiles of tamoxifen and the aromatase inhibitors in adjuvant therapy of hormone-responsive early breast cancer. Ann Oncol. 2007;18(Suppl 8):viii26-35.

39. Cuppone F, Bria E, Verma S, Pritchard KI, Gandhi S, Carlini $\mathrm{P}$, et al. Do adjuvant aromatase inhibitors increase the cardiovascular risk in postmenopausal women with early breast cancer? Meta-analysis of randomized trials. Cancer. 2008;112(2):260-7.

40. Henry NL, Azzouz F, Desta Z, Li L, Nguyen AT, Lemler $S$, et al. Predictors of aromatase inhibitor discontinuation as a result of treatment-emergent symptoms in early-stage breast cancer. J Clin Oncol. 2012;30(9):936-42.

41. Hershman DL, Kushi LH, Shao T, Buono D, Kershenbaum A, Tsai WY, et al. Early discontinuation and nonadherence to adjuvant hormonal therapy in a cohort of 8,769 early-stage breast cancer patients. J Clin Oncol. 2010;28(27):4120-8.

42. Partridge AH, LaFountain A, Mayer E, Taylor BS, Winer E, Asnis-Alibozek A. Adherence to initial adjuvant anastrozole therapy among women with early-stage breast cancer. J Clin Oncol. 2008;26(4):556-62.

43. Barron TI, Connolly R, Bennett K, Feely J, Kennedy MJ. Early discontinuation of tamoxifen: a lesson for oncologists. Cancer. 2007;109(5):832-9.

44. Murphy CC, Bartholomew LK, Carpentier MY, Bluethmann SM, Vernon SW. Adherence to adjuvant hormonal therapy among breast cancer survivors in clinical practice: a systematic review. Breast Cancer Res Treat. 2012;134(2):459-78.

45. Huiart L, Ferdynus C, Giorgi R. A meta-regression analysis of the available data on adherence to adjuvant hormonal therapy in breast cancer: summarizing the data for clinicians. Breast Cancer Res Treat. 2013;138(1):325-8.

46. Smith IE, Dowsett M. Aromatase inhibitors in breast cancer. N Engl J Med. 2003;348(24):2431-42.

47. Goldvaser H, Barnes TA, Seruga B, Cescon DW, Ocana A, Ribnikar D, Amir E. Toxicity of extended adjuvant therapy with aromatase inhibitors in early breast cancer: a systematic review and meta-analysis. J Natl Cancer Inst. (2018);110 (1).

Meta-analysis on the toxicity of extended adjuvant aromatase inhibitor therapy.

48. van Hellemond IEG, Vriens IJH, Peer PGM, Swinkels $\mathrm{ACP}$, Smorenburg CH, Seynaeve CM, et al. Ovarian function recovery during anastrozole in breast cancer patients with chemotherapy-induced ovarian function failure. JNCI. 2017;109(12)

49. Tjan-Heijnen VC, Hellemond IV, Vriens I, Peer P, Swinkels A, Smorenburg CH. Anastrozole after tamoxifen in early breast cancer patients with chemotherapy- 
induced ovarian function failure. J Clin Oncol. 2017;35(15_suppl):523.

50. Bellet M, Gray KP, Francis PA, Lang I, Ciruelos E, Lluch A, et al. Twelve-month estrogen levels in premenopausal women with hormone receptorpositive breast cancer receiving adjuvant triptorelin plus exemestane or tamoxifen in the suppression of ovarian function trial (SOFT): the SOFT-EST substudy. J Clin Oncol. 2016;34(14):1584-93.

51. Francis PA, Regan MM, Fleming GF, Lang I, Ciruelos E, Bellet $\mathrm{M}$, et al. Adjuvant ovarian suppression in premenopausal breast cancer. N Engl J Med. 2015;372(5):436-46.

52. Gnant $M$, Mlineritsch B, Stoeger $H$, LuschinEbengreuth G, Knauer M, Moik M, et al. Zoledronic acid combined with adjuvant endocrine therapy of tamoxifen versus anastrozol plus ovarian function suppression in premenopausal early breast cancer: final analysis of the Austrian Breast and Colorectal Cancer Study Group Trial 12. Ann Oncol. 2015;26(2):313-20.

53. Dignam JJ, Dukic V, Anderson SJ, Mamounas EP, Wickerham DL, Wolmark N. Hazard of recurrence and adjuvant treatment effects over time in lymph node-negative breast cancer. Breast Cancer Res Treat. 2009;116(3):595-602.
54. Ades F, Zardavas D, Bozovic-Spasojevic I, Pugliano L, Fumagalli D, de Azambuja E, et al. Luminal B breast cancer: molecular characterization, clinical management, and future perspectives. J Clin Oncol. 2014;32(25):2794-803.

55. Krop I, Ismaila N, Andre F, Bast RC, Barlow W, Collyar DE, et al. Use of biomarkers to guide decisions on adjuvant systemic therapy for women with early-stage invasive breast cancer: American Society of Clinical Oncology Clinical Practice Guideline Focused Update. J Clin Oncol. 2017;35(24):2838-47.

56. Sestak I, Cuzick J, Dowsett M, Lopez-Knowles E, Filipits M, Dubsky P, et al. Prediction of late distant recurrence after 5 years of endocrine treatment: a combined analysis of patients from the Austrian breast and colorectal cancer study group 8 and arimidex, tamoxifen alone or in combination randomized trials using the PAM50 risk of recurrence score. J Clin Oncol. 2015;33(8):91622.

57. Buus R, Sestak I, Kronenwett R, Denkert C, Dubsky P, Krappmann K, et al. Comparison of EndoPredict and EPclin with oncotype DX recurrence score for prediction of risk of distant recurrence after endocrine therapy. J Natl Cancer Inst. 2016;108(11):djw149. 